\title{
Psychoanalysis, Metaphor, and the Concept of Mind
}

\section{Jim Hopkins}

Freud's work has made it possible for us to extend thinking involving such concepts as desire, belief, and phantasy, and in a way which there is good reason to take as at least partly sound. In what follows I consider how this same work also extends thinking involving symbolism and metaphor, and how in this psychoanalysis is consilient with recent work on conceptual metaphor. The main example concerns the way we think about the mind. I argue that we can see such thinking as an important part of our concept of mind, and try, following Wittgenstein, to show how it provides an approach to the mind-body problem.

\section{Symbolic mapping in psychoanalysis.}

The development of the psychoanalytic view of the mind went hand in hand with the idea that much everyday mental life can be seen as informed by something like metaphor or symbolism. To see this let us take it that we begin with an understanding of intentional action as prompted (caused) by desire: we assume that successful action on a desire that $\mathrm{P}$ (e.g. that I get a drink) should bring it about that P (that I get a drink), so that the desire is satisfied; and this in turn should bring it about that the agent experiences or otherwise comes to believe that $\mathrm{P}$ (that I have got a drink), so that the desire is pacified, that is, ceases to govern action. We thus tacitly assume that the operation of desire is partly regulated by experience or belief, that is, by a form of representation of the situation in which desire is satisfied.

Freud's work indicates the regulation of desire by representation extends far beyond the case of intentional action. His discussions of dreams and symptoms, for example, enable us to see them as forms of representation which serve to regulate desires (or wishes) in the absence of any real satisfying situation. We can readily see this in the simple case in which someone thirsty dreams he is drinking, for here we have a desire that $\mathrm{P}$ (that I get a drink) which is temporarily pacified by an experience- or belieflike representation that $\mathrm{P}$ (I dream that I get a drink), without actual recourse to water.

In the Interpretation of Dreams Freud showed that the same pattern was to be found in more complex cases as well. Thus (p 106ff) his apparently non-wishful dream that his patient Irma was suffering from a toxic injection given by his colleague Otto could be seen as representing the satisfaction of, and thereby pacifying, a desire not to be responsible for Irma's continued suffering, which had been roused by a comment from Otto the day before, which Freud had taken as critical. In representing Otto as giving toxic injections, moreover, Freud seems also to have been pacifying a connected wish which originated years before: a wish not to have been responsible for the death of a patient by a toxic drug which he had administered, and that of a friend who had died as a result of injections of cocaine, which drug Freud had recommended to him. The pacification of a contemporary and potentially conscious desire concerning Irma went with together with that of deeper and presumably more painful desires originating from the past. 
Although the point is often missed, Freud's analysis of this dream can also be seen to support a distinct claim about representation in his waking life. In understanding the dream as representing the fulfilment of Freud's wish not to be responsible for the deaths of his injection-killed friend and patient, we take the figure of Irma in the manifest content of the dream to stand for, and so in this sense to symbolize, these other figures. But then it is also plausible to hold that these same relations -- relations of one figure standing for others -- also serve to explain aspects of Freud's waking motives and actions. For seeing that Irma stood in Freud's mind for these significant figures from the past apparently enables us to understand not only why he dreamt about her as he did (e.g. in terms of toxic injections) but also why in his waking life he reacted so strongly to Otto's comment about her, and with an attempt to justify his treatment of her (by writing up her case history) which preceded the fantastic elaboration of the same theme in his dream. Freud's analysis, that is, also suggests that the waking significance which Irma held for Freud before the dream was partly derived from that of the past figures and situations for which, as consideration of the dream showed, she stood in his mind.

The same applies to Freud's analyses of other dreams in which one person stands for another. So we can regard Freud's first extensions of commonsense psychology as providing tacit support for an idea about the significance we attach to persons and situations in daily life: present significant figures and situations partly inherit their meaning from past ones, to which they are unconsciously mapped. The role which such across-time and across-situation mapping could play was made clearer in further work. Thus consider the female patient discussed in the Introductory Lectures (1915, p 261-3). Her obsessional symptoms included a compusion to run repeatedly into a neighboring room, take up a particular postition beside a table, and ring for the maid, who after this -- the obsessional action completed -- had to be fobbed off with some pointless errand.

This patient, who was unhappily separated from her husband, related her symptom to her wedding night. Her husband had run repeatedly but unsuccessfully into her room try to have intercourse; and to avoid feeling ashamed before the maids he had faked a bloodstain on the sheets, but in the wrong place. This showed a series of links between the particulars of the symptom and the wedding night, which was completed when the patient took Freud to the table in front of which she stood, and explained that she took up her position in front of it in such a way that the maid could not fail to see a stain which was a prominent feature of the cloth. Thus in her symptomatic activity she was representing her wedding night, and pacifying her wish that things had been different then by showing the maid the stain which (stood for the earlier stain which) would have made clear that her marriage had been consummated.

\section{Symbolic representational pacification}

In this example there are both mappings between present and past persons, and also the less direct and so more recognizably symbolic instances of a table standing for a bed, a tablecloth for a sheet, and a stain from eating for a stain from sexual activity. These relations made it possible for a present intentional action (ringing for a maid and standing in a certain way) to provide representational pacification for desires relating to a situation long past. Such relations can also be seen in the transference, in which the analysand unconsciously maps past objects and situations on to the person and situation of the analyst, so that present activities again acquire a clearly a significance as pacifying desires or wishes originating in 
the past which can easily be discerned.

Freud also held that such symbolic relations were also naturally established over the course of a person's life. As early as 1895 he hypothesized a process of symbolic 'substitution':

...When an old maid keeps a dog or an old bachelor collects snuffboxes, the former is finding a substitute for her need for a companion and the latter for his need for -- a multitude of conquests....this normally operating mechanism of substitution is abused in obsessional ideas... (p 209)

Freud distinguished the mere setting up of a symbolic substitute for a past object of desire from the deeper process of transformation which he called sublimation, by which early sexual and aggressive motives obtained new and more acceptable objects. But post-Freudian work (see for example Segal 1957, 1978) indicates that these processes are best seen as intertwined. In consequence many analysts now regard symbol-formation as central to psychological development, and hence also to therapeutic success.

Something of the life-pervading role of symbolism hypothesized on this way of thinking can be illustrated by the example of a relatively successful teacher and writer, who was surprised when one of his pupils -who had made a special effort to be taught by him, and was trying hard to master his ideas -- offered to suck his penis. This offer was neither expected nor welcome, but that night the teacher dreamt that a lamb had come to suck milk from his finger.... On waking he realised that the lamb represented the pupil who had come to imbibe his ideas, and the milk-giving finger the penis his pupil had wanted to suck. So the dream could be seen as representing the fulfilment, in a form more acceptable because symbolic, of a sexual wish which had arisen on the day before.

The symbolism, however, went deeper, for the dream also represented him in the position of a mother nursing a child. His finger/penis was fulfilling the role of a feeding breast, and his writing and teaching represented as the production of milk as well as semen. The dream thus also expressed early desires for a combination of male and female roles which was incoherent and impossible to actually to attain, and which did not govern the dreamer's mature waking life. But owing to the symbolic meaning which he attached to his work, these desires could nonetheless still be pacified through it. For in writing or teaching the dreamer could with some justice see himself in reality -- to use metaphors which are more familiar and indirect -- as potent, seminal, and providing others food for thought.

Freud's work on symbolism and substitution thus made it possible to re-conceive desire in terms of an underlying continuity-in-difference which provides both a radically holistic perspective on the role of motive in the causation of action and a naturalistic description of the unconscious generation of present meaning from past experience. On this account the desires of childhood and infancy, while so unrealistic as commonly to be frustrated, are nonetheless not psychologically lost. Rather they are constantly rearticulated by mapping to new objects and situations, so as to direct action towards their symbolic representational pacification during the rest of life. New goals therefore acquire significance as representatives of the unremembered objects of our first and most visceral passions; and the depth of satisfaction we feel in present accomplishments flows from their unacknowledged pacification of unknown desires from the distant past. 


\section{Symbolic mapping in conceptual metaphor.}

According to the ideas we have been considering our thought and action about a present situation is likely to be at least partly derived from motives related to past situations to which the present is unconsciously mapped. This bears comparison with some claims recently advanced by George Lakoff and a number of his colleagues (see Lakoff 1993). These writers argue that metaphor should not be seen merely as a linguistic device, but rather as a form of thinking which is widespread, systematic, and fundamental. Their claim is that we very often think about objects, properties, or relations in one domain (called the target domain) by systematically mapping these onto objects and properties in another domain (called the source domain). The correspondence relation between these domains constitutes a potentially large and organized conceptual metaphor, by means of which we think, or conceive, the one domain in terms of the other.

Where the source domain is $\mathrm{A}$ and the target $\mathrm{B}$, so that in mapping the domains we think of B in terms of A, we can speak of the B as A metaphor. Thus we seem to make use of a metaphor of relationship as journey. In this we use concepts of objects, properties, and relations from the domain of travel or journeys in order to conceptualize objects, properties, and relations in the domain of co-operative personal relationships, such as love. In doing this we systematically take persons in such relations to correspond to travellers, their particular relationship to the vehicle in which they are travelling, and their goals in the relationship to their destinations in travelling. Thus we may speak of such a relationship as going along well, slowing down, going nowhere, getting stuck, at a crossroads, at a dead end, and so on.

In this metaphor, as in many others, the source domain in terms of which we think is intuitively more concrete than the target domain which we think about. Also we relate the domains tacitly, in the sense that we may be unaware both of using such correspondence relations, and of their richness and systematicity. Thus we may tacitly represent a relationship by one or another sort of vehicle, as seems appropriate to the rest of our thought. The relationship may be taking off (airplane); on the rocks(boat); off the rails (train); in the slow lane (car); and so on. A relationship which is taking off, say, will be one in which things are moving fast, and also getting better or more exciting, as in accord with such related metaphoric mappings as those of increase as upward motion (rising excitement, rising prices, rising in one's career, etc.) and better as higher (high status, high profile, high achiever, etc.) Thus it may be connected with the participants in the relationship feeling high on love, and so forth.

Further, as our understanding of familiar words enables us to form and understand new sentences, so our understanding of familiar correspondence relations enables us to form and understand new instances of metaphor. Thus, to take another of Lakoff's examples, in hearing a song lyric like 'We're driving in the fast lane on the freeway of love', we are immediately able to understand the metaphor in terms of the relationship-as-journey mapping, and others associated with it. The vehicle (relationship) is going fast, and this again is connected with excitement (fast cars, fast women); this speed, moreover, is compared to fast driving, which may be reckless or dangerous, and so lead to a crash in which someone will be hurt; the idea that the road is a freeway links with the idea of sexual freedom, free love, and so on. Such understanding ordinarily remains tacit, but in making it explicit we realize that it is already latent in our 
original response.

We also reason in terms such mappings. We take it, for example, that if a relationship is stuck, those involved have reason to try to do something about this. They may try to start over or to get the relationship started again, or to get goingor going forward, once more. Towards this end they may, for example, try to get over the problem, or to find their way out of the difficulty. Alternatively they may decide that the relationship has broken down, or perhaps been wrecked by the actions of one or both of them, in which case they will get out and go their separate ways.

Once we start to delineate such a metaphor, we can usually find additional examples, in which the hypothesized mapping serves to explain further responses we are aware of. Thus consider the phrase 'spaceship earth'. Why do these words evoke the idea that human beings have a significant co-operative relationship in virtue of being inhabitants of a common planet? This is explicable on the hypothesis that the phrase constitutes an instance of the correspondence between relationship and vehicle in the metaphorical structure we have been discussing. The metaphor, as we might say using another from the same family, reminds us that we are all in the same boat, and so should pull together. Again, one might ask why the song which begins 'Trains, and boats, and planes, all bound for Paris, New York, and Rome...' should be so evocative of solitude and loneliness. Here also there seems a plausible answer, in terms of the same metaphor: these vehicles which the singer is not in, going on journeys which the singer is not taking, represent relationships in which the singer, sadly, has no part. Such individual instances may not be particularly convincing one by one, but each mapping of the kind we are taking seems to generate a class of examples which is open and readily extensible, and which thus has considerable cumulative weight.

Students of conceptual metaphor have tried to show in detail how tacit mappings of this kind permeate our thinking about a great range of topics, including time and space, objects, events, and properties, logical and semantic categories, and the pursuit of human goals. They have also stressed how the ultimate source domain for many of these mappings is the human body (see particularly Johnston 1987). This work thus bears out William James's claim that

My own body and what ministers to its needs are thus the primitive object, instinctively determined, of my egoistic interests. Other objects may become interesting derivatively through association with any of these things, either as means or as habitual concomitants; and so in a thousand ways the primitive sphere of the egoistic emotions may enlarge and change its boundaries. (1980, Vol 1, 324)

\section{Pschyoanalytic findings about symbolic mapping complement those of conceptual metaphor, and link them with concrete thinking.}

The psychoanalytic hypotheses about symbolism sketched in section I complement these claims. Psychoanalysis is mainly concerned with the relations between past and present phantasies and desires, but takes these to be mediated by mappings which can be regarded as cognitive and metaphorical. Thus in the symptom of the table-cloth lady above, we find not only a cross-time mapping as between past and present, but also a cross-domain mapping as between eating and sexual activity (the mapped roles of bed 
and table, sheet and table-cloth, and the origins of the stains). The same domains, again, are mapped in the teacher's dream above, in which nutritive represents sexual sucking. Indeed an extensive metaphorical connection between eating and sexual activity seems part of the representational practice of every culture.

In representing many domains, according to psychoanalysis, we map them to relations to or among persons (object-relations), and our representations of present object-relations partly map them to past ones. The ultimate source for these mappings are therefore object-relations in childhood and infancy, which begin with those involving emotionally significant parts of the body and their functions. Both disciplines thus see conscious thought as underlain and informed by a system of mappings linking distinct objects and domains, a principle source of which is the human body.

Psychoanalysts and students of conceptual metaphor also conceive faulty symbolic/metaphoric thinking in ways which are closely related. Such thinking, as we have seen, maps objects, events, and properties across times and domains; and the sources of such mappings are often more concrete or basic, or more closely related to the human body, than the targets. It is therefore a requirement for such thinking that the source and target domains be both appropriately connected to, and appropriately differentiated from, one another. If sources are not appropriately connected with their targets they cannot be used to represent them; and if they are connected but not differentiated from their targets the one may be confused with the other. In both cases -- that in which the source of a would-be metaphor is not linked with a target, and that in which a source is confused with a target -- the metaphor is likely to be understood in terms of its source, and hence too concretely.

According to psychoanalytic theory as well as much psychological and psychiatric observation, such failures of source-target relations are shown in a number of psychological disturbances characterized by concrete thinking. For example Segal (1957) describes a concert violinist, who during a schizophrenc breakdown refused to play his violin. When asked why he replied 'Do you expect me to masturbate in public?' This can be understood in terms of two hypotheses: (i) that the significance of the man's violin playing was partly determined by a symbolic/metaphoric connection with earlier activity involving his own body, and (ii) that he had ceased to differentiate the source and target domains of this mapping. To take a different example, a ten-year-old autistic girl showed catastrophic anxiety when a nurse, about to do a blood test, said 'Give me your hand; it won't hurt.' She calmed down immediately when another person said 'stretch out your index finger'. She had apparently understood the nurse as requesting her to give her hand away, so that she would not have it afterwards. This too seems a case of concrete thinking, but one which may not require to be understood in terms of a collapse of source and target domains. Rather it may be that the girl simply understood 'give' in terms of the domain of the giving of objects from one person to another, and had not effected any further mapping.

Lakoff represents the maintenance of correct source/target relations in terms of what he calls the Invariance Principle. This principle, as he says,

...explains why you can give someone a kick, even if that person doesn't have it afterward, and why you can give someone information, even if you don't lose it. This is a consequence of the fact that inherent target domain structure automatically limits what can be mapped. (1993, p 215-6) 
To think that someone given a kick would possess that kick afterwards would be to fail properly to distinguish the source domain of physical objects transfered from one person to another in givings, from the target domain of kickings of one person by another. As in the examples above, this failure might arise either from confusion between source and target, or from an initial failure to use the source to map the target. Lakoff's invariance principle thus also marks the natural avoidance of concrete thinking which is characteristic of normal symbolic/metaphorical thought.

\section{Metaphoric representation and the concept of mind: the metaphor of the mind/body container.}

If metaphorical thinking is as important a part of our cognitive repertoire as analysts and students of conceptual metaphor claim, then we should be able to understand significant aspects our concepts in terms of it. I think that this holds for aspects of the concept of mind which have been particularly important for both philosophy and psychology, namely those which generate the problem of other minds and the problem of consciousness. We can begin to consider this by reviewing a family of metaphoric/symbolic mappings which represent the mind as a container, where the container in question might also be taken as the body. We can call this the metaphor of the mind/body container.

Some examples are particularly simple and direct, as when we say that a stupid or forgetful person -- one who cannot keep things in mind -- has a hole in his head. Others involve a variety of further comparisons. One familiar instance, for example, involves comparing the mind to the inhabitant of a house. There is a joke in which we knock on the forehead of an inattentive or vacant person, asking if anyone is at home. (There is also a children's game along the same lines, which even very little children instantly understand and enjoy.) Again, when a person's mind is not present, in one way or another, we may say that the lights are on(the eyes are open) but there is no one at home. Likewise we speak of the house of reason; of the mind as housed in the body; of the eyes as windows of the soul, the senses the doors of perception, portals of the mind, and so forth.

Metaphors from this family appear in very many contexts, as when we say that someone who has failed to keep something concealed has spilled the beans i.e. let them spill out of his mind/body container, and in a way that makes them difficult or impossible to replace. They are, however, particularly common in our conceptualisation of emotion and feeling (Kovecses 1990). Thus we speak of people as full of feelings of all kinds, which may bubble up, well up, or overflow, unless they are kept contained. We take it that if a person's feelings are bottled up then he or she should perhaps seek to express them, or let them out in one way or another, say by channelling them into to an activity like art or exercise, venting them by talking to an acquaintance, or even taking them out on the cat, or something of the kind. Otherwise the pressure of feeling may be damaging or dangerous.

A number of the variants of this metaphor are highly detailed and systematic. Thus, for example, we seem to conceive certain emotions as fluids in the mind/body container. We think of anger, for example, as a hot fluid: the feelings of someone who is angry may seethe or simmer and so are agitated. A person who is hot under the collar in this way may be fuming as the anger rises, or wells up in him; and so he may have to simmer down, or cool down, so as not to boil over. If he can't do this, and doesn't somehow 
manage to let off steam he may be at risk of bursting with anger, or exploding with rage. The spectrum of feeling between calmness and uncontrollable anger is thus represented relatively strictly in terms of the temperature of the emotion-liquid, which may be cool (no anger), agitated or hot (some degree of anger), or boiling (great anger). By contrast a source of fear may make one get cold feet or make one's blood run cold, so that, in the extreme case, cold fear or icy terror may render one frozen to the spot and so unable to move. Here the opposition in the nature of the feelings in marked by one in the properties of the metaphorical fluids to which we map them.

Where we take the mind/body container as enclosing feelings, we also take it that emotionally significant events may affect the container itself. This happens when we become frozen to the spot, for in this case the coldness of the contents of the mind/body container are represented as affecting (immobilizing) the bodily container. The container can be put at risk from within, from the kind of eruption in which someone blows his top, flips his lid, or blows his stack. The container can also suffer damage which originates outside, as when a person is crushed, shattered, or broken. Particularly serious is the kind of episode in which a person cracks up in such a way that the mind/body container is entirely fragmented. Such involuntary fragmentation is quite different from the small and precisely controlled exchange, in which we give another a piece of our mind. In this case we are relieved of our aggression, which is metaphorically passed on to the other, who has now to cope with it. This is different from the case in which a person goes to pieces so completely as to lose his mind.

Our taking the mind/body as a container has a further aspect, which is that we liken good things to those we would like to take into the container, particularly by eating, and bad things to those which should be put or kept out, and by processes which include excretion. Thus, in general, we regard good things as sweet : life is sweet, youth is sweet, peace is sweet, and so, according to our way of speaking, are hope, freedom, victory, revenge, nothings whispered in the ear, people's faces, a moment's relief, dreams, babies (whom one could sometimes just gobble up, because they are so sweet and delightful), children (particularly little girls, who as we know are made of sugar and spice), young animals, melodies both heard and unheard, and an endless variety of other things.

The idea of having good things in the container also applies to other persons in the environment. Those whom we love, for example, we keep in mind, keep in our memories, and keep in our heart; and this -strikingly -- goes with a capacity actually to feel the other as a represented and valued presence somehow inside us, as if they had in some sense actually been internalized. Hence also the characterization of things which are good or desirable as things we would like to eat is especially striking in the case of love and lust. Terms of endearment include numerous variations on honey, sugar, sweetness, and the like; she or he may be the cream in my coffee, the sugar in my tea, my sweetie-pie, and so on. There are also variants of these expressions which extend to coarser appetites, such as that for cheesecake or beefcakeor meat; and one can want to meet a dish or a hunk, or take an interest in very many other bodily things compared to food. This is another aspect of the metaphorical comparison between nutrition and sexuality, which also appears fleetingly in the symptom of the table-cloth lady and the dream of the successful teacher above.

As indicated, we often represent communication of thought and feeling in terms of actual or attempted transfer of things from container to container. The eyes can be used to transfer the temperature of 
emotion, for example, as when they set one alight (afire, aflame, etc.), or when one is frozen by an icy look or a cold stare. Again, opinions and sentiments are put into words -- which can therefore be full of meaning, not, say, hollow or empty -- and thus given to others (passed to them, exchanged with them, etc.) who may or may not receive, or take them in. This kind of transfer of thought or feeling can also affect the mind/body container towards which it is directed: just as another's words may convey or carry things from their container to ours, so their words or deeds may strike us, and they may penetrate, pierce, perforate, cut, sting, lacerate, lash, or otherwise attack or injure the mind/body container. One may be stabbed by a sharp look, as by sharp words, even if the person is not looking daggers at one; and looks and words may also be acid, poisonous, or full of venom. Also the mind can be entered, or threatened with entry, in other ways which are connected with bodily entry, as when someone gets under our skin, gets up our nose, or again bugs us like some insect intruding on the body.

Since we represent what is in the mind/body container as having great power to affect it, the question of what we take in from what others attempt to put across is highly significant. We seem to regard various forms of truth as providing food for thought, and hence intellectual nourishment, and various forms of falsehood in an opposite way. Just as we systematically relate anger or fear to metaphorical internal fluids, so we systematically relate the badness of various kinds of misrepresentation to the unpleasantness or toxicity of the materials in terms of which we represent them. Thus we may hold that bad ideas or opinions are tosh, trash, rubbish, garbage, or even horse manure or bullshit, and we characterize their sources in related ways. If someone's utterances or opinions are without substance we may say that they are just gassing. If someone regularly engages in bragging or other relatively harmless and self-inflating misrepresentation we may say that they are full of hot air. We may call someone who is fluent at minor misrepresentation a piss-artist; and someone prone to more serious or pernicious misrepresentation will be said to be full of piss, or, if the falsehood is still more noxious, full of shit.

Likewise we may say that opinions which we characterize in this way stink, and regard them as distasteful, repellent, repulsive, disgusting or nauseating. Hence we hope that no one (or at least no one who is not some kind of sucker) will be inclined to swallow them. But people may imbibe such falsehoods in childhood, or be fed them through propaganda, in which case their minds may be infected or poisoned, without their being able to do anything about it. Contaminating, corrupting, or polluting others with ideas of this kind is decidedly not giving them the proper intellectualsustenance. Hence if people air such unsanitary views, or try to force such filth or junk into others' minds, or down their throats, they are at risk of being told to shove it, that is, to put these things back into the inner space of their own mind/body containers, and by a route which reflects their nature.

This sample of our thought and talk can be taken to indicate that we have a metaphorical representation of the mind as a container, which we can diagram as follows:

Figure 1: The metaphor of the mind as a container

\section{This metaphor is extensively used in unconscious representation of the mind.}

This too is continuous with that we find in psychoanalysis. Thus consider the following from Kohut's 
(1977, p 105) accountof what he calls 'indescribable states of self-dissolution'.

...Here are some examples taken at random from my psychoanalytic practice: a negligible crack in the plaster in one room might indicate the presence of a serious structural defect of the patient's house; a tiny skin infection of the patient or of someone he experiences as an extension of himself is the first sign of a dangerous septicaemia; or, in dreams, the frightening infestation of the living quarters with spreading vermin; or the ominous discovery of algae in the swimming pool. Much as these fears might occupy the patient's mind, however, leading to states of endless brooding, worry, or panic, these fears do not constitute the core of the disturbance, but have been generated as a result of the patient's attempt to give a circumscribed content to a deeper unnameable dread experienced when a person feels that his self is becoming seriously enfeebled or is disintegrating. The ability of the analyst to conceive of psychic conditions that cannot be described in terms of verbalizable meaning allows him to consider an important band in the spectrum of possibilities as he scrutinizes the analysand's anxiety -- the fragmentation of and the estrangement from his body and mind in space, the breakup of his sense of continuity in time.

Although Kohut takes these examples 'at random', it is clear that they have something in common. The representations by which these patients register their dread that something is going seriously wrong with their selves are all versions of the metaphoric representation of the mind/body container described above. In each case -- the plaster cracking in the house, the living quarters invaded with vermin, the infected skin, the fluid-filled pool infested with algae -- the mind/body container and/or its contents are represented as threatened. So the states which Kohut regards as indescribable are nonetheless naturally expressed through what we have seen as a systematic metaphor, as instances in which the house of reason, or the fluids of emotion and feeling, are in one way or another endangered.

This kind of metaphorical/symbolic representation of the self, moreover, is familiar from many other psychoanalytic sources. It has a clear role, for example, in the dream of Irma's injection. Freud remarks that the toxic solution which the dream represents Otto as having injected into Irma is in fact a chemical which he took to be involved in the sexual process, and that this was related to his having thought that Irma's problems were the result of her widowhood, and might be relieved by the accompaniments of marriage. (As he says in his letter in Abraham (1965), discussing the 'sexual megalomania' which he took to underlay the dream, 'There would be one simple therapy for widowhood, of course. All sorts of intimate things, naturally.') Thus the dream is constructed around a mapping as between the intellectual sexual solution which Freud was offering Irma, and the physical and toxic sexual solution, which Otto was portrayed as injecting into her mind/body container (using his own dirty syringe).

\section{This representation has also been assigned an important theoretical role.}

Owing to its clinical frequency, this representation of the mind also plays an important role in psychoanalytic theory. Freud described the mind as it appears in this kind of portrayal in terms of an 'internal world', which he took to be related to 'the most basic instinctual impulses' of taking in and putting out (1940, p 205). This he described in terms of a 'bodily ego', which was 'ultimately derived from bodily sensations, chiefly those springing from the surface of the body' and so 'a mental projection of the surface of the body' (1923 p 26, authorized footnote). We may take this together with Freud's account of 
some aspects of early mental life, in which he says that our attitudes of acceptance and rejection as applied to thoughts are originally related to taking things into and out of the body.

Expressed in the language of the oldest -- the oral -- instinctual impulses, the judgement is 'I should like to eat this', or 'I should like to spit it out'; and, put more generally: 'I should like to take this into myself and to keep that out.' That is to say: 'It shall be inside me' or 'It shall be outside me.' As I have shown elsewhere, the original pleasure-ego wants to introject into itself everything that is good and to eject from itself everything that is bad $(1925, \mathrm{p} 26)$.

If we remember that this is said to be at the root of attitudes towards thoughts themselves, and take the space into which the good is introjected and bad expelled to be that established as inner by 'a projection of the surface of the body', we arrive at a representation of the mind which accords with the metaphoric picture as diagrammed above very closely.

This representation has also figured extensively in post-Freudian thinking. Melanie Klein (1975) found such an internal world to be shown in a multiplicity of ways in the representational activities of little children, where it was related to the inside of the mother's body as well as the children's own; and Wilfred Bion $(1967,1977)$ made the role of containment for this world explicit in his discussions of container and contained.

\section{Multi-domain mapping.}

Although students of conceptual metaphor characteristically speak of cross-domain mapping, psychoanalytic instances often show mappings involving serveral domains at once. This is so, for example, in the dream of the successful teacher. For the dream showed not only a clear representation of sexual by nutritive sucking, but also a phantasy -- upon which the student also seems to have been acting -that the teacher's knowledge could be internalized in this concrete way. Hence it also involved an instance of the mind/body container, and a particular form of concrete thinking about knowledge, the possibility of which is foreshadowed also in the metaphors (imbibing ideas, food for thought, etc.) noted above. (The same holds for the intellectual/sexual solution as represented in the dream of Irma's Injection.)

This kind of multi-domain mapping frequently figures in phantasies of internalization, in which good things or persons are represented as taken into the self. This is particularly notable, for example, in representations involving the automobile. People very often represent themselves in terms of their cars, or their cars as extensions of themselves. (This seems to be one cause of road rage.) But cars are also vehicles, and so that travelling in them is also used to represent relationships to others. This, as well as the role of concrete thinking about the mind, is illustrated by the case of the 'mechanical boy' discussed by Bettelheim $(1959,1967)$.

This little boy, diagnosed as autistic, was fascinated by machines of various kinds, and identified himself with them. He converted his bed, for example, into a complex car-machine that would 'run him' or 'live him': this included a carburettor which enabled him to breathe, a motor that ran his body, a 'speaker' that 
enabled him to talk or hear, and so forth. In this he gave the clearest possible indications of the way he took this car as representing, and extending, his self; and this was also the topic of many of his drawings and other communications. But the symbolism was shown to have a further significance in an interview with the boy several years later. As he then said:

I can remember being interested in mechanical and electrical things almost as far back as I can remember...I made a car...that's one of the main things I made out of the bed...it was something in which a person was enclosed...when I started coming closer to people...I'd have fantasies about a car or anything that moved on wheels that was enclosed and I'd have a fantasy that I was in it myself...I'd always picture that somebody else was in it with me...one person was Barbara, and it was right after I'd been here a year and a half that I had put up a device on my bed to make it [the bed] look like a car. I told her to get on the bed while I pretended to drive the car...on other occasions I pretended to drive home, you know, to where my family was. And mostly, I think, it was a way of thinking of the time when I would be living with my family and would trust people enough to want them. (1967, p 334)

Here we see a double use of the metaphors we have considered. The car was an enclosed space which by which the little boy represented his self, and into which he wanted to bring those he might trust and relate to, as in accord with the metaphor of the mind as container; but as a vehicle it also provided an instance of the metaphor with which we began, that of relationship as journey. In this case, however, the metaphor was used concretely: wanting to ensure and extend the functioning of his self, and also to form relationships, the boy actually constructed an enclosed space which was also a vehicle, as if thereby constructing a relating self. As he later realized, however, this was not a way of bringing such things about, but rather 'a way of thinking' -- a form of thinking in terms of metaphor or symbolism -- of relationships which he might yet form. His improvement went with a recognition of the symbolic nature of what he had previously confused with the real.

It is now widely recognized that many individuals diagnosed as autistic have difficulty in employing the commonsense concept of mind. Most work in this field (Baron-Cohen et al 1993; Baron-Cohen 1995) has concentrated on the understanding of propositional attitudes like belief. It seems, however, that there may also be significant difficulty in employing the conception of the mind as a container, which is a focus in psychoanalytic treatments of autism. Workers in this field often quote the example of an observant autistic youth who said 'People talk to each other with their eyes...What is it that they are saying?' (Frith 1993) The discussion above indicates the extent to which we articulate the language of the eyes via the metaphor of the mind as a container. Lack of the capacity to use this metaphor seems an important aspect of failure to conceptualize the mind.

\section{Metaphoric representation and the mind-body problem: the problem of other minds and the problem of consciousness.}

The use of the metaphor of the mind as a container thus seems integral to our way of thinking about the mind, and also liable to go wrong in certain ways. Let us now consider the role of this metaphor in philosophy. 
Philosophical thinking about the mind has been dominated by two related problems: the problem of consciousness, and the problem of other minds. We can think of these problems as arising as follows: the experiences which present the world to us seem to be internal to the mind, whereas the world which they present seems external to it. Thus when I feel pain or see a tree, the experience of pain, or the visual impression of the tree (and the visual field of which it is a part) are internal to me, and hence presented in introspection, whereas the tree itself, by contrast, is part of the external world. These internal experiences, moreover, seem to have a phenomenal character, which we cannot envisage being possessed by any external physical thing. This character seems subjective, in the sense that what it is, is wholly and fully presented in how it seems in introspection; whereas an external physical thing like a tree is objective, in the sense that there is a potentially rich distinction between how it seems in perception and how it is in itself. Finally, the internal experience seems private, in the sense that it can be introspected or apprehended only by one person, the person to whose mind it is internal, whereas a physical thing is public, in the sense that in the sense that it can be perceived and hence known about by more than one person.

Taking the case of visual perception, we can present these contrasts in the form of a diagram as follows:

Figure 2: The dualistic image of the mind.

The oppositions diagrammed here seem conceptual or logical. It seems a part of our way of thinking about these matters that no one thing could be both internal to the mind in the way experiences are, and also external to it in the way physical things are; and likewise that the same thing could not be both introspectible and externally perceiveable, phenomenal and physical, subjective and objective, or private and public. Hence this picture gives rise to dualism, the view that mental phenomena are not physical phenomena, and hence that human experience does not, as we have every scientific reason to believe, go on in the brain or nervous system. Also, and connectedly, it gives rise to the problem of consciousness, and that of other minds.

The problem of consciousness is that of understanding how events in the brain could realize, or otherwise produce, the distinctive properties apparently manifested in experience. This problem is not solved by accepting that mental events do in fact occur in the brain, for the difficulty is precisely that of understanding how this can be so -- how events which occur in the brain, and hence are physical, public, and objective, can be phenomenal, subjective, and private, as experiences seem to be. Hence it is also not solved by holding that mental events can have aspects or properties which are phenomenal, subjective, or private, since this again is a version of what requires to be explained. Nor finally is it solved by supposing that we have distinctive first-person ways of thinking or modes of presentation of the neural events which realize our experience, although this certainly seems to be so. For the question remains, as to how and why these modes of presentation should render neural events phenomenal, subjective, and private, or make them seem so despite their physical nature. To many, therefore, this problem suggests the need for a new approach, or even a new science. Thus in a recent collection of articles (Metzinger 1995), the situation is described as follows:

To be able to speak seriously about a science of consciousness, a number of fundamental questions would 
have to be answered. It is interesting to note that with the emergence of consciousness private worlds -spaces of inner experiences -- are opened up. These spaces, however, are individual spaces: ego-centres of experience that suddenly appear in a centerless universe. Each such centre of consciousness constitutes its own perspective on the world. This perspective is what philosophers sometimes like to call the 'firstperson perspective'. A phenomenal world of its own is tied to each of these perspectives. These individual worlds of experience also possess a historical dimension: almost always a psychological biography emerges together with them -- what we call our 'inner life'. This too can be seen as the history of the genesis of a world, or a phenomenal cosmology: within each of us a cosmos of consciousness unfolds temporarily, a subjective universe develops. The first part of the problem is to understand how a variety of subjective universes can constantly form and disappear in our objective universe...

The problem of other minds is also a direct consequence of this picture, for according to it an other's experiences are internal and private, and hence inaccessible to me and not part of the external world in which I locate that other. This being so, it seems I can know nothing about the other's experiences, and indeed can have no reason to assume that an other has experience. For if all that the other does -- all the ways the other's body moves, for example -- can be taken to flow from events in his brain that are distinct from experiences, why should I postulate anything further? And even if I identify the other's experiences with events in his brain, still I seem to have no access to the phenomenal character of those experiences, and hence might well still wonder how far they are comparable to mine.

\section{Wittgenstein's claim that these problems are due to metaphor.}

As is familiar, Wittgenstein (1954) held that philosophical problems arise, among other ways, from metaphors or comparisons between the way we use words in different regions of language, and applied this with particular effect to the problems of mind. These, he said, arose from a 'picture' of the mind:

425. In numberless cases we exert ourselves to find a picture and once it is found the application as it were comes about of itself. In this case we already have a picture which forces itself upon us at every turn, -- but does not help us out of the difficulty, which only begins here...

427. "While I was speaking to him I did not know what was going on in his head." In saying this one is not thinking of brain-processes, but of thought-processes. The picture should be taken seriously. We should really like to see into his head. And yet we only mean what elsewhere we should mean by saying we should like to know what he is thinking. I want to say: we have this vivid picture -- and that use, apparently contradicting the picture, which expresses the psychical.

This picture, as Wittgenstein describes it, emerges as the dualistic picture of the mind described above. In it the mind is conceived as an enclosed space, distinct from the space inside the body, whose contents are in themselves psychological and phenomenal rather than physical ('one is not thinking of brain-processes, but of thought-processes'), and detected by a process analogous to sight (introspection). Wittgenstein observed that the privacy which this picture gave to phenomenal properties would render them incapable of description in a public language, and so incommunicable. He took this as a clear reductio of the view, which he put as follows: 
293. If I say of myself that it is only from my own case that I know what the word "pain" means -- must I not say the same of other people too? And how can I generalise the one case so irresponsibly? Now someone tells me that he knows what pain is only from his own case! --- Suppose everyone had a box with something in it: we call it a "beetle". No one can look into anyone else's box, and everyone says he knows what a beetle is only by looking at his beetle. -- Here it would be quite possible for everyone to have something different in his box. One might even imagine such a thing constantly changing. -- But suppose the word "beetle" had a use in these people's language? -- If so it would not be used as the name of a thing. The thing in the box has no place in the language-game at all; not even as a something: For the box might even be empty. -- No, one can 'divide through' by the thing in the box; it cancels out, whatever it is.

That is to say: if we construe the grammar of the expression of sensation on the model of 'object and designation' the object drops out of consideration as irrelevant.

Here the argument clearly turns on an instance of the container metaphor, that is, the box which represents the mind. So, as we can say, Wittgenstein took the dualistic image of the mind, which we have portrayed in Figure 2 above, as a particular instance of the metaphor of the mind as a container, which we have portrayed in Figure 1. The problem of other minds is thus partly constituted by the imposition of this metaphor.

Wittgenstein seems to have taken the same metaphor to give rise to the problem of consciousness; but in this case he does not seem to have been able to make the connection fully explicit. For example he writes:

296. "Yes, but there is something there all the same accompanying my cry of pain. And it is on account of that that I utter it. And this something is what is important -- and frightful." -- Only whom are we informing of this? And on what occasion?

297. Of course, if water boils in a pot, steam comes out of the pot and also pictured steam comes out of the pictured pot. But what if one insisted on saying that there must also be something boiling in the picture of the pot?

We can describe Wittgenstein's thinking here as follows. Things happen in our bodies which cause the verbal and other behaviour through which we express pain, as things happen in a boiling pot which cause the expression of steam. (The box in the previous metaphor is replaced by the pot in this.) In order to understand these internal events we form a representation (picture) of them in terms of the mind/body container (the picture of the pot). But in using this picture, we perforce represent the internal events as occurring, not in the physical space of the body where they actually occur, but rather as in a space of a distinct kind. We are misled by our form of representation, in such a way that we think of the internal events with which we are concerned as occurring not in the pot (the body), but in the picture of the pot (the metaphorical space internal to the mind/body container).

\section{The metaphor of containment and the notion of a virtual inner space.}

Wittgenstein's thinking here is very compressed, but we have reason to consider it worth exploring. We have stressed in previous sections how metaphorical/symbolic thinking is an important part of our 
conceptual repertoire, and how representations of the mind as a container pervade both our conscious and unconscious thinking. Wittgenstein's analysis of these problems thus represents them as springing from a preconscious mode of thought to which we have access through other disciplines, and which we have other grounds for considering as significant.

We can make his claim clearer via the notion of a virtual space. A virtual space is one which is not real, but an artefact of our modes of representation. We create a virtual space if we treat a space which is in fact only represented or imagined as if it were real. Thus we can think of the space shown in a mirror, not as that of the actual room, including ourselves, which is reflected in it, but as an alternative space which we might enter by passing through the looking glass. In this case the space through the looking-glass is a virtual space -- a space we can consider in detail, think of ourselves as entering and having adventures in, etc., but a space which nonetheless is not real. We can treat the space preesnted by a cinema or television screen, or that shown in a video game, in the same way; and if the representation of space with which we are dealing is part of a sufficiently comprehensive and compelling illusion, we may characterize it as a virtual reality. Taking a virtual space as a real space, in turn, is an error in representation comparable to concrete thinking. In this case the source for a representation is linked, not with the real or imaginary domain which it should represent, but with an alternative imaginary domain, taken as real.

This in the notion involved in Wittgenstein's metaphor. Someone who insisted that there had to be something boiling in a picture of a pot would be taking a represented space, represented as having something boiling in it (the picture of the boiling pot) as a real space with someone boiling in it, and so would be creating a virtual space in the sense above. (The space in the pictured pot would be like the space behind the looking glass, taken as real.) So the idea which we are to consider is that the distinct inner space in which we are inclined to insist that conscious events go on is in fact a virtual space, and therefore an artefact of our representation of the mind as a container. Thus take the 'phenomenal cosmology' introduced by Metzinger above, with its range of 'individual spaces', which constitute 'subjective universes', which appear with birth and disappear with death. The view under consideration is that this picture is not literally true. It is not actually the case that the physical space in the vicinity of persons or other conscious creatures is like a Swiss cheese, filled with other spaces of a mysteriously different kind containing experiences. Rather on this account the spaces Metzinger is talking about -- and those depicted in the figures we have drawn above -- are virtual spaces, things that we are inclined to take as real spaces because of the way we represent them in spatial terms.

\section{Virtual inner space and the representation of real inner events.}

Wittgenstein's comparison has a second aspect, which is that the metaphor of the mind as a container actually serves as a representation of events in the body. (The picture of the boiling pot, although it does not actually contain anything boiling, does nonetheless represent the boiling in the pot.) We can see this clearly in the connected case of thinking of anger as a hot fluid inside us, or representing emotion in terms of internal fluids generally. This way of thinking serves as a representation of things that go on in us when we experience emotion, and hence it serves as a representation of physical processes which are otherwise unknown to us, but which are in fact contained within the body. In speaking of levels of temperature of an imaginary emotion-fluid, for example, we seem to be indexing levels of behaviour-governing 
neurophysiological processes, particularly those which are occurring in the autonomic nervous system. Since this system produces and monitors emotion-related changes in the guts, for example, it seems that we are mapping its activity in feeling that our guts have run cold, or turned to water, or whatever. How such mappings work in detail we have yet to discover, but it seems reasonable to suppose that they underpin the metaphor.

As a first approximation, therefore, we can see the metaphor of the mind as a container as representing something inner by something inner: we can take the representation of the mind as an inner space as a primitive natural way of representing the working of the nervous system in the space inside the body. This seems to apply to the metaphoric picture generally, for the business of getting good (for us) things into the body and keeping bad (for us) things out of it is one of the basic things we think the brain and nervous system are designed to do, and this holds for animals of all kinds. This mode of representation, however, seems designed to work in the absence of explicit knowledge about its representational function. Hence the question whether we are dealing with a representation of the real space inside our bodies, or an alternative virtual space, will depend upon how we construe the representation in question.

\section{Virtual inner space and the apparently non-physical features of consciousness.}

This approach enables us to use the account of metaphoric representation discussed above to explain the features of mind which we regard as problematic. Recall that in thinking of the mind as a container, it is essential that we not do so in too concrete a manner. For example if we think of anger as a hot fluid inside us, and so actually feel the anger in this way, we still do not think that if someone's anger wells up, boils over, or spills out, this anger will subsequently be found spattered on the carpet. To use the metaphor thus would clearly be to think of anger and its locus in too concrete a way, and most people automatically do not do so. Rather we subtly and systematically de-concretize and so de-physicalize both the space occupied by the anger-as-fluid and the metaphoric fluid itself.

This means that we tacitly treat the anger-space as a non-physical space, not to be confused with the actual internal space with which, nonetheless, it may phenomenologically overlap; and likewise we treat the anger-fluid as a non-physical fluid, not to be confused with physical things actually inside us. To say this, however, is to say that the anger-fluid and the anger-space are virtual entities, which we represent as differing from the real ones on which they are modelled. Still we can see that this representational dephysicalization actually involves nothing which is really non-physical. Rather it flows from the tacit imposition of the requirement of avoiding concrete thinking (something like the invariance principle) upon a mapping which has both physical sources (physical fluids and containers) and physical targets (changes inside the body involved in emotion). Since nothing which is both real and non-physical actually comes into question, we can say that the apparent non-physicality of the anger-space and fluid are a sort of cognitive illusion, engendered by this spatial mode of representing the inner. So it seems that the same process might likewise account for the apparent non-physicality of the inner space and contents involved in our everyday conception of the mind.

If this approach is correct, then it may be possible to see the features of experience which constitute the problem of consciousness as virtual properties, that is, as appearances engendered by our way of 
representing the neural events which realize experience. This would be a substantive account of the way our modes of presentation generate the problem of consciousness. On this account the problematic distinction between the inner and the outer would be engendered by our representing experience as occurring in one or another kind of inner field or space -- visual space, auditory space, the space in which we feel pain, etc. -- where these were 'spaces' were modelled on space as it appears to us in perception. (This is the role of the container metaphor.) This means, in effect, that we do not directly represent them as in the bodily space in which they actually are, but rather use an image derived from the perception of space outside the body, which is therefore liable to be understood as that of a distinct virtual space.

We can perhaps start to see this in the dualistic image of visual experience, as portrayed in Figure 2. In this case we seem to be representing neural events in the visual system by a straightforward mapping from outer to inner -- a metaphoric internalization of the space and process of visual perception itself. It is as if in this way of thinking of experience the ordinary space in which we see things had simply been transposed inside (and hence stripped of its physical substance and made the object of a further special sense) so as to become the non-physical, quasi-spatial visual field, which we think of as somehow internal. So long as we think of the mapping in question as just a mode of representation of what is inside the body, it presents no difficulty; but if we construe it in terms of an alternative virtual space, we perforce feel that the entities and properties displayed in that space are not those of concrete physical things, and hence regard them as phenomenal. Again, if we represent something as phenomenal just insofar as we represent it as perceived within a virtual internal space, then there will be no more to phenomenal objects than is manifested in the space in which they appear, so that what is phenomenal will also be subjective. So this approach may also go some way towards explaining why we feel that the esse of phenomenal properties is their percipi, and why these properties seem, puzzlingly, both distinct and yet not distinct from our apprehension of them. And finally, since these virtual properties are represented as perceived within the space representing a single mind, they also seem private.

These remarks are of course only indications of an approach, and to be taken seriously the acccount hinted at here would require to be developed in greater detail. Still they suggest that the kind of metaphorical or symbolic mapping studied in psychoanalysis or as conceptual metaphor may structure our thinking about the mind in the way Wittgenstein seems to have envisaged. In this respect the role of metaphoric/symbolic mapping may be deeper than the disciplines which explore it have so far hazarded. 